\title{
Zellweger Syndrome: Diagnostic Assays, Syndrome Delineation, and Potential Therapy
}

\author{
Golder N. Wilson, Ronald G. Holmes, Joseph Custer, Jeffrey L. Lipkowitz, \\ Joan Stover, Nabanita Datta, and Amiya Hajra \\ Departments of Pediatrics (G.N.W., J.C., J.S.), Ophthalmology (J.L.L.), and \\ Biochemistry (N.D., A.H.), University of Michigan, Ann Arbor, and Division of \\ Pediatric Gastroenterology (R.G.H.), William Beaumont Hospital, Detroit, Michigan
}

\begin{abstract}
Patients with the cerebrohepatorenal syndrome of Zellweger lack peroxisomes and certain peroxisomal enzymes such as dihydroxyacetone phosphate acyltransferase in their tissues. Deficiency of this enzyme, which is necessary for glycerol ether lipid synthesis, provides a biochemical method for recognizing patients with subtle manifestations of Zellweger syndrome and suggests the utility of exogenous ether lipid precursors as a therapeutic strategy for these children. We describe the results of glycerol ether lipid supplementation to two children, one with classic Zellweger syndrome and 9\% of control fibroblast dihydroxyacetone phosphate acyltransferase activity, and one with mild facial manifestations, wide sutures, hypotonia, developmental delay, hepatomegaly, peripheral retinal pigmentation, and $50 \%$ of control fibroblast dihydroxyacetone phosphate acyltransferase activity. An increase in erythrocyte plasmalogen levels following therapy was clearly demonstrated in the milder patient, and neither patient showed evidence of toxicity. Evaluation of therapy by comparison to the usual clinical course of Zellweger syndrome was not helpful because of the variability and incomplete documentation of 90 previously reported cases. The literature survey did provide criteria for classic Zellweger syndrome, which include hypotonia with or without deformation of limbs, large fontanels and split sutures, prominent forehead, flattened facial profile with hypoplastic supraorbital ridges, anteverted nares, highly arched palate, cryptorchidism or labial hypoplasia, hepatomegaly or elevated liver enzymes, peripheral pigmentation of the retina, renal cortical cysts, and characteristic neuropathology involving decreased myelinization, abnormal neuronal migration, and sudanophilic macrophages. Less severe patients, as exemplified by our case 2 and others from the literature, will not have all the classic features and can be
\end{abstract}

Received for publication March 21, 1985; revision received June 22, 1985.

Address reprint requests to Golder N. Wilson, M.D., Ph.D., Rm A717, Montreal Children's Hospital, McGill University, 2300 Rue Tupper, Montreal, PQ H3H 1P3, Canada.

(C) 1986 Alan R. Liss, Inc. 
recognized only by a growing panel of biochemical indicators. Our patient studies illustrate the complexity of designing comprehensive therapy for Zellweger-like conditions, suggest other diseases that may involve peroxisomal alterations, and emphasize the need for multicenter, collaborative studies to evaluate biochemical heterogeneity and therapy of peroxisomal disorders.

Key words: Zellweger syndrome, peroxisomes, glycerol ether lipids, plasmalogens, MCA/MR syndrome

\section{INTRODUCTION}

Zellweger syndrome (ZS) is a fatal autosomal recessive disorder; affected individuals have unusual physical features, severe neurologic dysfunction, hepatorenal disease, and diverse metabolic abnormalities [Bowen et al, 1964; Kelley, 1983]. The important role of peroxisomes in lipid metabolism [Novikoff and Novikoff, 1982] and their absence from ZS liver [Goldfischer et al, 1973] suggested that peroxisome deficiency may account for many alterations in ZS. Brown et al [1982] and Moser et al [1984] have demonstrated that very long chain fatty acids are increased in the plasma and fibroblasts of ZS patients, a finding that correlates with the selective oxidation of very long chain fatty acids by peroxisomes [Kawamura et al, 1981]. The report by Heymans et al [1983] showing decreased plasmalogens in several ZS tissues supported the findings of Hajra [1968], Hajra et al [1979], and Hajra and Bishop [1982], who demonstrated that certain enzymes necessary for plasmalogen biosynthesis are located in peroxisomes. This finding of plasmalogen deficiency led to studies by Schutgens et al [1984] and Datta et al [1984] demonstrating that the first enzyme in the pathway for plasmalogen synthesis (Fig. 1)-ie, dihydroxyacetone phosphate acyltransferase (DHAP-AT)--was deficient in the liver, leucocytes, and fibroblasts of ZS patients.

Elevated very long chain fatty acid levels or deficiency of DHAP-AT thus provide prenatal [Solish et al, 1985; Hajra et al, 1985] or postnatal diagnostic assays for ZS, although normal levels in parents indicate that neither assay is a measure of the primary defect. In fact, since elevated long chain fatty acids [Moser et al, 1984] and DHAP-AT deficiency [Hajra, personal communication] also occur in infantile adrenoleukodystrophy, these biochemical changes should be viewed as general characteristics of peroxisomal alteration, which must be associated with specific diagnostic categories by further morphologic and biochemical delineation. Nevertheless, since soluble peroxisomal enzymes and the distal enzymes of plasmalogen synthesis have significant activity in ZS fibroblasts [Datta et al, 1984; Wanders et al, 1984], dietary supplementation of plasmalogen precursors in order to bypass the DHAP-AT deficiency represents a possible strategy for treatment of this disorder. Incorporation of alkylglycerols into plasmalogens proceeds normally in ZS fibroblasts [Schrakamp et al, 1985].

We report on a therapeutic trial of dietary ether lipid supplementation in a classic severe ZS patient and in one with milder symptoms that were diagnosed by documenting partial deficiency of DHAP-AT. Therapy appeared promising in the partially deficient patient, as judged by clinical improvement. Assessment of this treatment, particularly by comparison to historical controls, emphasizes the need for prospective evaluation of patients with $\mathrm{ZS}$ and related peroxisomal disorders. 


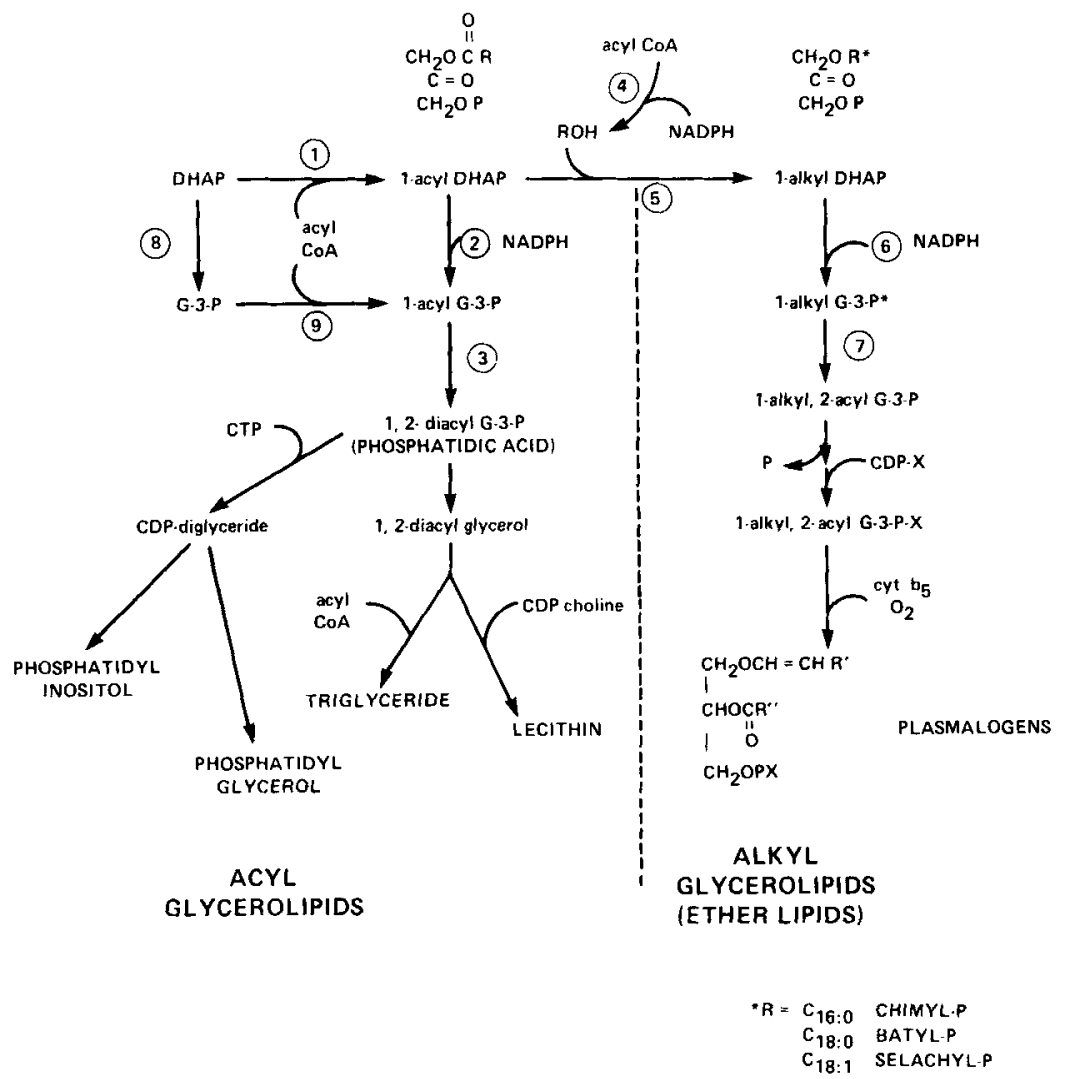

Fig. 1. Pathways for acylglycerol and glycerol ether lipid synthesis. After synthesis from acyl coenzyme A and DHAP (reaction 1), acyl DHAP is a precursor for both acyl and alkyl glycerol lipids. Reduction of acyl DHAP to I-acyl glycerol-3-P (reaction 2) is one route for acylglycerolipid synthesis. Alternatively, acyl DHAP reacts with long chain alcohol to form 1-0-alkyl DHAP (reaction 5), the precursor for ether glycerolipid and plasmalogen synthesis. The enzymes catalyzing reactions 1 (DHAPAT), 5 (alkyl DHAP synthase), and 2 or 6 (acyl/alkyl DHAP:NADPH oxidoreductase) are localized mostly in peroxisomes and constitute the sole pathway for ether lipid synthesis, while G-3-P acyltransferase (reaction 9) is located mostly in mitochondria and microsomes. Deficiency of DHAP acyltransferase with residual activities of enzymes catalyzing reactions 2,5,6, and 9 in ZS provides the rationale for correcting tissue plasmalogen deficiency by providing oral mixtures of chimyl, batyl, and selachyl alcohols.

\section{CLINICAL REPORTS}

\section{Patient 1 (Fig. 2A)}

This patient was described briefly in a prior report [Datta et al, 1984]. She was the $4.05-\mathrm{kg}$ (97th centile) product of a 43-week uncomplicated gestation to a $G_{2} P_{0}$ $\mathrm{Ab}_{1}$ 23-year-old mother and 30-year-old father. The family history was unremarkable. Her length was $51 \mathrm{~cm}$ (25th centile), occipitofrontal circumference (OFC) was $35 \mathrm{~cm}$ (60th centile), the interpupillary distance was $4.5 \mathrm{~cm}$ (90th centile), and the intercanthal distance was $2.6 \mathrm{~cm}$ ( $>97$ th centile). Facial anomalies included a high forehead, broad nasal root, highly arched palate, anteverted nares, micrognathia, and a flattened profile with hypoplastic supraorbital ridges. The anterior and posterior 

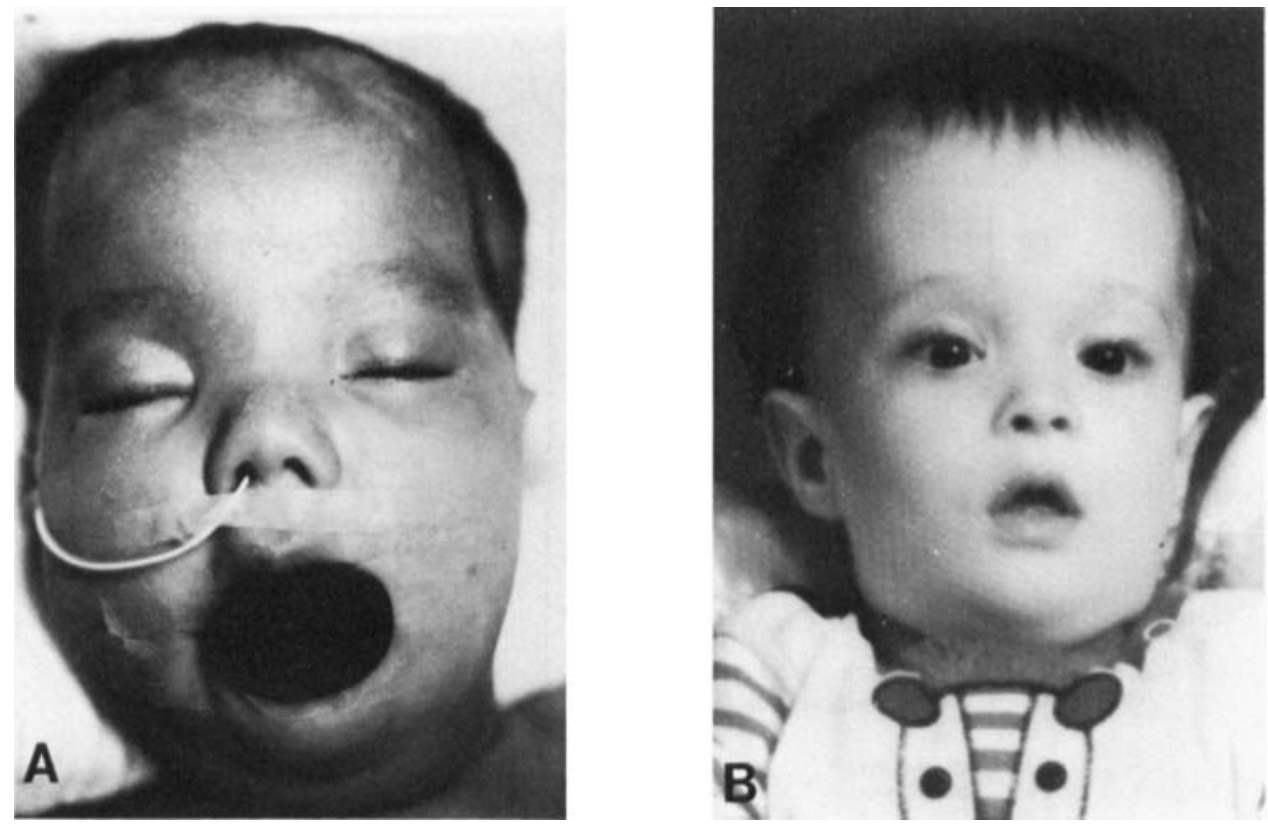

Fig. 2. Patient 1 (A-age 6 weeks) and 2 (B-age 8 months).

fontanels were enlarged and showed open metopic and sagittal sutures. There were epicanthal folds, upslanting palpebral fissures, Brushfield spots in the irides, cortical cataracts, and peripheral pigmentation of the retina. Other abnormalities included redundant nuchal skin, widely spaced nipples, hepatomegaly extending $4 \mathrm{~cm}$ below the right costal margin, bilateral simian creases, bilateral talipes equinovarus, hypoplastic labia majora, and severe hypotonia. Neonatal intensive care for seizures and persistent fetal circulation included ventilator support, Priscoline ${ }^{\circledR}$, and phenobarbital therapy. Computerized tomography (CT) scan and screen for congenital infection were normal, as were chromosomes. Serum iron was 112, total iron binding capacity was 370 , serum glutamic oxaloacetic transaminase (SGOT) was 60 units per liter, and serum glutamic-pyruvic transaminase (SGPT) was 39 units per liter at age 1 week.

At age 5 weeks, a skeletal survey showed patellar enlargement with punctate calcification around the hips and retarded bone age; urine metabolic screen showed qualitatively elevated pipecolic acid, and renal ultrasound showed increased echogenicity with no visible cysts. Deterioration began at age 12 weeks with increasing seizures and respiratory insufficiency. Trials of ether lipid supplementation are summarized in Figure 3. At age $81 \frac{1}{2}$ months, the patient was stable at home but exhibited no developmental progress. The height was $70 \mathrm{~cm}$ (50th centile), weight was $8.71 \mathrm{~kg}$ (50th centile), OFC was $44.5 \mathrm{~cm}$ (50th centile), and the anterior fontanel was markedly enlarged $(8 \mathrm{~cm}$ long by $6 \mathrm{~cm}$ wide). At age 10 months, she developed severe gastrointestinal bleeding and died from acute renal failure and respiratory insufficiency. A limited autopsy confirmed the cause of death and showed hepatomegaly and renal cortical cysts.

\section{Patient 2 (Fig. 2B)}

This patient is a 20 -month-old white male who was referred to evaluation of hypotonia, hepatomegaly, and failure to thrive. He was the $3.15-\mathrm{kg}$ (25th centile), 54- 


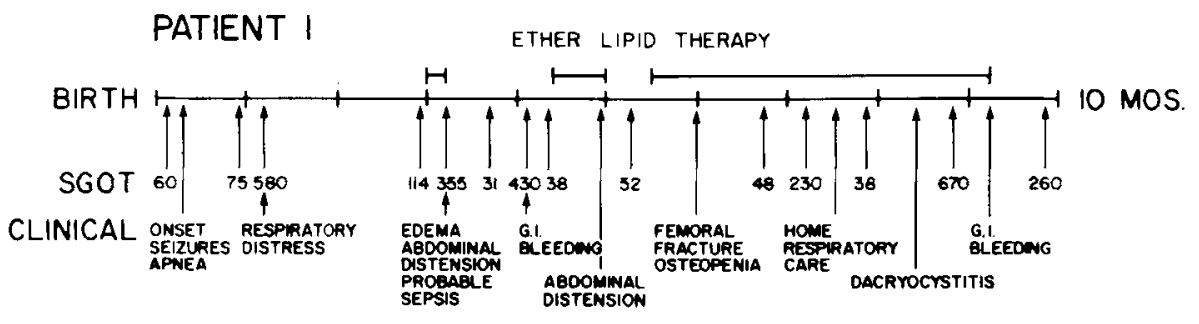

\section{PATIENT 2}

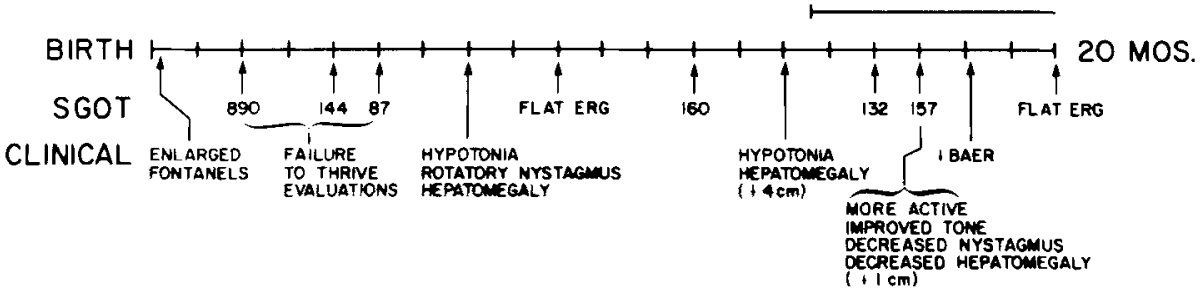

Fig. 3. The clinical course and timing of ether lipid supplementation for patients 1 and 2. G.I., gastrointestinal; ERG, electroretinogram; BAER, brainstem auditory evoked response. Periods of ether lipid supplementation are indicated above the time line by bars $(\vdash)$.

$\mathrm{cm}$ (90th centile) product of a term uncomplicated gestation to a 23-year-old primigravida. The father was 27 years old and unrelated to the mother. Enlarged anterior and posterior fontanels with a widened sagittal suture were noted at birth; the OFC was $34.5 \mathrm{~cm}$ (60th centile). A cranial ultrasound study and skull films were normal. Admission at age 7 weeks demonstrated an open metopic suture, enlarged anterior ( 3 $\times 3 \mathrm{~cm})$ and posterior $(1.5 \times 1.5 \mathrm{~cm})$ fontanels, a highly arched palate, poor head control, and slightly increased deep tendon reflexes. He had mild anemia (hemoglobin 10.1 with normal red cell indices) with elevations of the following: serum bilirubin (1.2 mg per $\mathrm{dl}$ ), alkaline phosphatase (495 units per liter), SGOT (912 units per liter), thyroid stimulating hormone (TSH) (21 IU per $\mathrm{ml}$ ), and thyroid hormone (T4) (12.6 $\mu \mathrm{g}$ per $\mathrm{dl}$ ), iron saturation ( $51 \%$, compared to a normal of $20-25 \%)$, and ferritin $(814$ ng per $\mathrm{ml}$ ). A urine amino acid screen, erythrocyte protoporphyrin, hemoglobin electrophoresis, TORCH screen, and serologic markers for $\mathrm{HBV}$ infection were normal. Percutaneous liver biopsy showed increased glycogen with fibrous septa and paucity of intrahepatic biliary ducts. At age 9 months, ophthalmologic evaluation showed inconsistent fixation and following of light, vertical nystagmus, right esotropia, punctate cortical and nuclear sclerosis lens changes bilaterally with no cataracts, marked peripheral retinal pigmentary changes, and gray optic discs of normal size. Visual evoked response and electroretinogram performed under general anesthesia showed no photopic or scotopic responses, suggesting a poor outlook for vision. At age 14 months, the patient's height was $78 \mathrm{~cm}$ (50th centile), weight was $8.8 \mathrm{~kg}$ (5th centile), OFC was $47 \mathrm{~cm}$ (25th centile), and the anterior fontanel continued to be enlarged $(8 \times 6 \mathrm{~cm})$ with an open metopic suture. The posterior fontanel was closed. He had long eyelashes, a broad nasal root (intercanthal distance $2.4 \mathrm{~cm}-50$ th centile; interpupillary distance $4.5 \mathrm{~cm}-50$ th centile), a shallow nasal bridge, a highly arched palate, an enlarged liver that was palpable $5 \mathrm{~cm}$ below the right costal margin, increased joint laxity with hypotonia, and increased deep tendon reflexes. An initial lipoprotein electrophoresis showed a low or absent pre-beta band that suggested abetalipoproteinemia, but two subsequent analyses were normal. Chromosomes and 
leucocyte lysosomal enzyme panel were normal. Muscle biopsy of the rectus abdominus showed normal muscle with predominance of type I fibers. Continued slow growth, poor vision, hypotonia, and developmental delay prompted a trial of oral ether lipid supplementation at age 141/2 months (Fig. 3). At age 20 months, increased very long chain fatty acids (C26 of $1.49 \mu \mathrm{g} / \mathrm{ml}$ vs $0.33 \mu \mathrm{g} / \mathrm{ml}$ for control; C26/C22 0.225 vs 0.04 for control) were detected in the serum [Moser, personal communication].

\section{METHODS}

Assays for DHAP-AT, acyl/alkyl DHAP reductase, alkyl DHAP synthase, and glycerol-3-phosphate acyl transferase were performed as described previously [Datta et al, 1984]. Fibroblasts were trypsinized, washed with $25 \mathrm{mM}$ Tris- $\mathrm{HCl}, 5 \mathrm{mM} \mathrm{KCl}$, $140 \mathrm{mM} \mathrm{NaCl}, 0.5 \mathrm{mM}$ EDTA at pH 7.4 and stored frozen before assay. Frozen liver or fibroblasts were homogenized in 10 volumes of $0.25 \mathrm{M}$ sucrose containing Tris$\mathrm{HCl}(10 \mathrm{mM}, \mathrm{pH} 7.4)$ and EDTA $(1 \mathrm{mM})$ prior to assay.

Plasmalogens were measured on packed red cells that had been washed as described for fibroblasts. Lipids were extracted with chloroform-methanol and washed as described by Folch et al [1957], and plasmalogens were assayed from $0.5 \mathrm{ml}$ of packed red cells using the methods of Horrock [1968]. Quantitative measurements of alkylglycerol ethers and plasmalogens were performed by treating the lipid extract with Red-Al followed by thin-layer chromatography [Wood and Synder, 1968].

The ether lipid mixture for patient 1 contained $400 \mathrm{mg}$ of chimyl alcohol (see Fig. 1), $400 \mathrm{mg}$ of batyl alcohol, $200 \mathrm{mg}$ of selachyl alcohol, $150 \mathrm{mg}$ of egg lecithin, and $200 \mathrm{mg}$ of sodium deoxycholate (all from Sigma Chemical Co., St. Louis, MO) in $100 \mathrm{ml}$ of water emulsified by sonication in a Branson sonifier for 15 minutes at $70 \%$ power with the large probe. For patient 2, the selachyl alcohol and egg lecithin were omitted. Each patient received $1 \mathrm{ml}$ of ether lipid suspension five times daily with feedings, representing $50 \mathrm{mg}$ ether lipid per $5-8 \mathrm{~kg}$ daily for patient $1(6-10 \mathrm{mg} /$ $\mathrm{kg}$ ) and $40 \mathrm{mg}$ ether lipid per 7-10 kg daily for patient $2(4-6 \mathrm{mg} / \mathrm{kg})$. These dosages are well below those amounts of alkylglycerols that have been administered to adults without complication [Mangold, 1973].

\section{RESULTS}

Table I summarizes the activities of DHAP-AT and other enzymes in the fibroblasts and liver from patients 1 and 2. Whereas classic ZS patients such as patient 1 have negligible fibroblast DHAP-AT activity [Datta et al, 1984], patient 2 has $50 \%$ of control activity, which correlates with his milder phenotype. Liver DHAP-AT activities are negligible in both cases, whereas other lipid-synthesizing enzymes have intermediate activity. This may reflect their dependence upon peroxisome structure or, in the case of glycerol-3-phosphate acyltransferase, concurrent alterations of mitochondria and the endoplasmic reticulum which have been reported in ZS [Goldfischer, 1973].

Figure 3 illustrates the course of ether lipid therapy in both cases. Patient 1 received therapy for about 5 months during the indicated periods with interruptions owing to suspected infection or gastric distension. Patient 2 has received therapy for $5 \frac{1}{2}$ months continuously without obvious complications such as elevated liver enzymes or gastrointestinal problems. No subjective or objective benefits of therapy 
TABLE I. Activities of Lipid-Synthesizing Enzymes in Patients 1 and 2

\begin{tabular}{|c|c|c|c|c|}
\hline & \multirow[b]{2}{*}{ PH } & \multicolumn{3}{|c|}{$\mathrm{nmol} / \mathrm{min} / \mathrm{mg}$ protein } \\
\hline & & Patient 1 & Patient 2 & Control \\
\hline \multicolumn{5}{|c|}{ DHAP Acyltransferase } \\
\hline \multirow[t]{2}{*}{ Fibroblast } & 7.4 & $0.01^{\mathrm{a}}$ & 0.14 & $0.28 \pm 0.05^{a}$ \\
\hline & 5.5 & $0.02^{a}$ & 0.13 & $0.27 \pm 0.03^{\mathrm{a}}$ \\
\hline \multirow[t]{2}{*}{ Leucocyte } & 7.4 & 0.01 & 0.06 & 0.16 \\
\hline & 5.5 & 0.02 & 0.06 & 0.26 \\
\hline \multirow[t]{2}{*}{ Liver } & 7.4 & $\mathrm{ND}^{\mathrm{h}}$ & 0.05 & 0.46 \\
\hline & 5.5 & & 0.08 & 0.36 \\
\hline \multicolumn{5}{|c|}{ Glycerol-3-phosphate acyltransferase } \\
\hline \multicolumn{2}{|c|}{ Fibroblast } & $0.65^{a}$ & 1.15 & $1.28 \pm 0.20^{\mathrm{a}}$ \\
\hline \multicolumn{2}{|l|}{ Leucocyte } & 0.10 & 0.11 & 0.31 \\
\hline \multicolumn{2}{|l|}{ Liver } & ND & 0.46 & 0.55 \\
\hline \multicolumn{5}{|c|}{ Alkyl DHAP synthase } \\
\hline \multicolumn{2}{|c|}{ Fibroblast } & $0.02^{\mathrm{a}}$ & 0.08 & $0.14 \pm 0.02^{\mathrm{a}}$ \\
\hline \multicolumn{2}{|l|}{ Liver } & ND & 0.14 & 0.35 \\
\hline \multicolumn{5}{|c|}{ Alkyl/acyl DHAP: NADP reductase } \\
\hline \multirow{2}{*}{\multicolumn{2}{|c|}{$\begin{array}{l}\text { Fibroblast } \\
\text { Liver }\end{array}$}} & $1.36^{\mathrm{a}}$ & 1.42 & $1.48 \pm 0.18^{a}$ \\
\hline & & ND & 0.91 & 1.09 \\
\hline
\end{tabular}

${ }^{\text {a}}$ From Datta et al [1984].

$\mathrm{b}_{\mathrm{ND}}=$ not done.

could be discerned for patient 1, and the occasional increases in hepatic enzyme levels were thought to be due to other causes as they did not always correlate with the initiation or cessation of ether lipid supplementation.

After three months of therapy, the parents and physicians involved with patient 2 noted improvement of growth (increasing from the 5th to 25 th centile) and muscle tone (acquisition of sitting-up and cruising skills). He had decreased nystagmus with improved ability to fixate and to follow light. A fundoscopic examination showed gray optic discs with virtual disappearance of the prominent retinal pigmentation observed at age 9 months. However, an electroretinogram repeated at age 20 months again showed an extinguished response that was essentially unchanged from the previous study.

An increase in erythrocyte phosphoethanolamine plasmalogen levels in patient 2 at both $5 \frac{1}{2}$ and $7 \frac{1}{2}$ months after ether lipid supplementation is shown in Table II. Little change was observed in other lipid classes. Quantitative plasmalogen determinations were not performed on patient 1 . Baseline erythrocyte plasmalogen levels in patient 2 were higher than those for patients with classic ZS [Heymans et al, 1983], a feature consistent with his milder phenotype.

\section{DISCUSSION}

Complementary advances in the understanding of peroxisome function and the consequences of peroxisome deficiency in ZS have provided diagnostic assays and therapeutic strategies for this severe malformation syndrome. The need to evaluate biochemical heterogeneity and potential therapy in ZS prompted a review of those ZS patients reported in the literature or seen at our institution. Clinical and pathologic 
TABLE II. Phospholipid Composition of Erythrocytes (Patient 2) Before and After Ether Lipid Therapy $^{*}$

\begin{tabular}{lrrrr}
\hline & \multicolumn{3}{c}{ Age (months) } & Control \\
\cline { 2 - 5 } Lipid class & \multicolumn{1}{c}{$\mathbf{1 4}$} & 20 & 22 & 5.1 \\
Polar lipids & 7.8 & 8.1 & 4.5 & 11.0 \\
PS + PI & 12.6 & 12.2 & 9.8 & 30.5 \\
Sphingomyelin & 29.4 & 26.1 & 23.8 & 2.1 \\
PC plasmalogen & 2.7 & 2.3 & 2.0 & 31.5 \\
PC & 34.5 & 32.9 & 34.9 & 9.5 \\
PE plasmalogen & 4.0 & 7.9 & 9.8 & 10.2 \\
PE & 9.4 & 12.4 & 15.1 & \\
\hline
\end{tabular}

*Values represent percent of total phospholipids as PS, phosphatidyl serine; PI, phosphatidyl inositol; PC, phosphatidyl choline; PE, phosphatidyl ethanolamine. Erythrocyte samples were obtained at age 14 months (before treatment), 20 months (after $5 \frac{1}{2}$ months of treatment), and 22 months (after $7 \frac{1}{2}$ months of treatment).

features of 83 literature cases and 7 cases of our own (not including patients 1 and 2) who were judged to have classic ZS are summarized in Table III. Excluded from the survey were cases that were minimally described or atypical, eg, those of Gatfield et al [1968] or Thomas et al [1975] in which high serum pipecolic acid levels were present but the typical clinical features were absent.

Common manifestations such as hypotonia with or without accompanying deformations, large fontanels and split sutures, hepatomegaly or elevated liver enzymes, peripheral pigmentation of the retina, and the typical malformations (high forehead, flattened facial profile, simian creases, malformed ears, high palate, shallow/broad nasal bridge with anteverted nares, cryptorchidism, or labial hypoplasia) should prompt consideration of a Zellweger-like condition. Patient 1, for example, had 28 of 32 features for which she was evaluated in Table III (44 features total) and would represent a classic ZS patient. Patient 2 had only 15 of 32 features in Table III and represents a new disease category with partial manifestations of ZS which can be recognized by clinical and biochemical criteria. Other patients who might be included in this category are those with pipecolic aciduria [Thomas et al, 1975; Gatfield, 1968], those with infantile adrenoleukodystrophy [Brown et al, 1982], those with infantile Refsum's disease [Poulos et al, 1984], and the atypical case of Versmold et al [1977].

Previous results from our laboratories [Datta et al, 1984], as summarized in Table I, suggest that the enzyme DHAP-AT has an obligate relationship to peroxisome biogenesis and is almost completely deficient in tissues of patients with classic ZS. Enzymes such as catalase, which in many normal tissues are located in peroxisomes, can assume a cytoplasmic location in ZS and have normal activity. Enzymes such as alkyl DHAP synthase and acyl/alkyl DHAP reductase (reactions 5 and 2 or 6 in Fig. 1) have either an intermediate dependence on peroxisome biosynthesis or are partially distributed in peroxisomal and microsomal compartments in normal cells; such enzymes have intermediate activities in ZS tissues. Glycerol-3-phosphate acyltransferase is not primarily located in peroxisomes and is used as a reference activity in our clinical assays. Partial reduction of this activity in certain ZS tissues may reflect concomitant alteration of mitochondria and endoplasmic reticulum as suggested by Goldfischer et al [1973].

Peroxisome-dependent enzymes such as DHAP-AT, while not useful as a measure of the primary defect [Datta et al, 1984], provide a good criterion for peroxisomal 
TABLE III. Clinical Manifestations of Classic Zellweger Syndrome*

\begin{tabular}{|c|c|c|c|c|c|}
\hline & \multicolumn{3}{|r|}{ Male } & \multicolumn{2}{|c|}{ Female } \\
\hline Cases & \multicolumn{3}{|r|}{47} & \multicolumn{2}{|l|}{43} \\
\hline Mean birth weight & \multicolumn{3}{|r|}{2,740} & \multicolumn{2}{|c|}{2,730} \\
\hline Prenatal growth failure & \multicolumn{3}{|r|}{$6 / 47(13 \%)$} & \multicolumn{2}{|c|}{$11 / 43(25 \%)$} \\
\hline Postnatal growth failure & & & $25 / 27(92 \%)$ & \multicolumn{2}{|c|}{$19 / 20(95 \%)$} \\
\hline $\begin{array}{l}\text { Mean age at death } \\
\text { (No. patients-wk) }\end{array}$ & & & $38-12.2$ & \multicolumn{2}{|c|}{$41-12.9$} \\
\hline \multirow{2}{*}{$\begin{array}{l}\text { Mean age of survivors } \\
\text { (No. patients - wk) }\end{array}$} & & & $8-130$ & $2-72$ & \\
\hline & \multicolumn{3}{|c|}{ Incidence $\%$} & \multicolumn{2}{|c|}{ Incidence \% } \\
\hline \multicolumn{3}{|l|}{ Craniofacial } & \multicolumn{3}{|l|}{ Limbs } \\
\hline “Dysmorphic facies" & $78 / 80$ & 98 & Talipes equinovarus & $33 / 59$ & 56 \\
\hline Large fontanelle & $44 / 47$ & 94 & Ulnar deviation & $9 / 59$ & 15 \\
\hline High/prominent forehead & $47 / 50$ & 94 & Camptodactyly & $6 / 59$ & 10 \\
\hline Flat supraorbital ridges & $24 / 26$ & 92 & Simian creases & $26 / 33$ & 79 \\
\hline Epicanthal folds & $31 / 56$ & 55 & Radiographic stippling & $41 / 59$ & 69 \\
\hline "Hypertelorism," broad nasal & & & Genitals & & \\
\hline root & $33 / 48$ & 69 & Cryptorchidism & $27 / 36$ & 75 \\
\hline Anteverted nares & $9 / 11$ & 82 & Clitoral hypertrophy/ & & \\
\hline Highly arched palate & $31 / 43$ & 72 & hypoplastic labia & $5 / 9$ & 56 \\
\hline Malformed ears & $35 / 39$ & 90 & Neurologic & & \\
\hline Deafness & $5 / 5$ & 100 & Hypotonia & $83 / 84$ & 99 \\
\hline Congenital cataracts & $30 / 42$ & 71 & Seizures & $35 / 44$ & 80 \\
\hline Pallid/hypoplastic optic disc & $5 / 14$ & 36 & Pachymicrogyria & $31 / 46$ & 67 \\
\hline Retinal pigmentary changes & $9 / 24$ & 38 & Heterotopias/abnormal migration & $22 / 46$ & 48 \\
\hline Hepatorenal & & & Subependymal cysts & $17 / 46$ & 37 \\
\hline Hepatomegaly & $54 / 78$ & 69 & Astrocytosis, gliosis & $16 / 46$ & 35 \\
\hline Elevated liver enzymes & $32 / 43$ & 74 & Sudanophilic macrophages & $12 / 46$ & 26 \\
\hline Gastrointestinal bleeding & $13 / 20$ & 65 & Abnormal myelinization & $10 / 46$ & 22 \\
\hline Cirrhosis & $30 / 49$ & 61 & Hypoplastic corpus callosum & $9 / 46$ & 20 \\
\hline Hepatic iron storage & $17 / 27$ & 63 & Hypoplastic olfactory lobes & $3 / 46$ & 7 \\
\hline Renal cortical cysts & $54 / 58$ & 93 & Laboratory & & \\
\hline Albuminiria & $4 / 14$ & 29 & Elevated serum iron & $13 / 21$ & 62 \\
\hline Aminoaciduria & $8 / 19$ & 42 & Elevated urine pipecolate & $20 / 26$ & 77 \\
\hline \multicolumn{6}{|l|}{ Adrenal } \\
\hline Low weight & $6 / 7$ & 86 & & & \\
\hline Striated adrenocortical cells & $7 / 8$ & 88 & & & \\
\hline
\end{tabular}

*Patients are summarized from the reports of Agamonolis et al [1976], Arneson et al [1982], Bartoletti et al [1978], Bowen et al [1964], Brun et al [1978], Danks et al [1975], Deleon et al [1977], Evrard et al [1978], Garzuly et al [1974], Gilchrist et al [1976], Govaerts et al [1983], Gustafsson et al [1983], Hittner et al [1981], Jan et al [1970], Liu et al [1976], Opitz et al [1969], Passarge and McAdams [1967], Patton et al [1972], Poznanski et al [1970], Punnett and Kirkpatrick [1968], Sommer et al [1974], Smith et al [1965, Vincens et al [1973], Volpe and Adams [1972], and Williams et al [1972]. The patients of Vitale et al [1969] appear to be included in the report of Opitz et al [1969].

alteration, as demonstrated by the partial deficiency in patient 2 . One can speculate that one or more proteins responsible for peroxisome biogenesis will represent the gene product(s) altered in Zellweger-like conditions and that DHAP-AT activity is in some way dependent upon normal peroxisome structure. Since DHAP-AT is unstable, it is extremely important to include control tissues stored under equivalent conditions and to assay related enzymes as an indicator of tissue preservation before concluding that there is a partial deficiency. 
Because deficiency of DHAP-AT would predict deficient synthesis of glycerol ether lipids and plasmalogens, as has in fact been documented in ZS [Heymans et al, 1983], a trial of oral glycerol ether lipid therapy was tried in both patients. Oral supplementation definitely increased erythrocyte plasmalogens in patient 2 (Table II), as measured by quantitative thin-layer chromatography. Such increases must reflect incorporation of alkylglycerols into membrane lipids during erythropoiesis, as the distal enzymes for plasmalogen synthesis (Fig. 1) are not present in circulating erythrocytes. The lack of consistent side effects in either patient (Fig. 3) supports the low risk status of glycerol ether lipids previously deduced by oral administration to adults [Mangold, 1973]. While striking, the apparent clinical improvement in patient 2 must be viewed with skepticism until better delineation of peroxisomal disorders and their natural history is achieved. Also, conclusions about neurologic improvement should await definitive proof of the ability (not unlikely for lipid-soluble molecules) that alkylglycerols cross the blood-brain barrier. An attempt to compare the influence of therapy in patient 1 to the usual natural history of ZS was frustrated by the variable severity and incomplete documentation of ZS patients illustrated by the data in Table III. Improvement in growth and overall nutrition was noted in patient 1 after therapy, but the incidence of complications seemed similar to those of previously reported patients. No developmental progress was noted.

Obviously, oral ether lipid therapy and the rather arbitrary mixture of alkyl glycerols employed here represents only a beginning in the treatment of the multiple consequences imposed by peroxisome deficiency. Comprehensive therapy for peroxisome deficiencies might involve dietary restriction of long chain fatty acids, since these have been shown to be exogenously provided [Kishimoto et al, 1980], and provision of bile salts [Hanson et al, 1979] in addition to ether lipid supplementation. Replacement of adrenal steroids should also be considered, particularly during stress [Govaerts et al, 1984]. Even with these efforts, coexisting alterations of mitochondrial and microsomes [Goldfischer, 1973] might not be amenable to treatment in severely affected patients.

One may ask whether patient 2 has a mild form of ZS or another disease such as infantile adrenoleukodystrophy. While patients with infantile adrenoleukodystrophy lack the pronounced facial changes, renal cortical cysts, and skeletal anomalies associated with ZS, they do have peroxisome deficiency, elevated very long chain fatty acids, pipecolic acidemia, altered bile metabolism, hypotonia, and demyelinization in common with ZS [Goldfischer et al, 1985]. In addition, six previously reported cases of neonatal adrenoleukodystrophy [Ulrich et al, 1978; Benke et al, 1981; Jaffe et al, 1982; Haas et al, 1982] have exhibited a severe degenerative course, although one patient's development peaked as late as age 2 years [Haas et al, 1982]. The wide fontanels and split sutures of patient 2 , along with the subtle facial anomalies and improving clinical course lead us to classify him as a mild form of ZS. Patient 2 illustrates the need for a multicenter prospective registry to aid in the differential diagnosis, biochemical delineation, and assessment of treatment for patients with peroxisomal disorders.

Once systematic investigation is initiated, there is likely to be a large list of disorders that involve alteration of peroxisome function. Both Refsum's disease and cerebrotendinous xanthomatosis may belong to a peroxisomal disease category [Goldfischer, 1982\} and have responded to therapy based on dietary avoidance of phytanic acid or supplementation of a deficient metabolite (bile salts). Abetalipoproteinemia is 
another disorder worth evaluating for peroxisomal alterations, because (1) certain infants with that disorder have had severe hypotonia and retinitis pigmentosa, (2) certain ZS patients including patient 2 have had transient reports of low betalipoprotein, and (3) there is a clear relationship between peroxisome density and lipoprotein metabolism as indicated by the effects of clofibrate [Reddy et al, 1982]. The increased hepatic glycogen in classic or mild ZS, particularly in our patient 2, also suggests a link between peroxisome or endoplasmic reticulum alterations and glycogen metabolism.

The implications of peroxisome deficiency and altered lipid metabolism as a central cause for the altered morphogenesis in ZS are many. A clear relationship among peroxisome function, lipid metabolism, and neurogenesis now exists and can be defined in animal models. Certain of the many neurologic mutants of the mouse are well worth screening for peroxisomal alterations. The cause of disorders involving cerebral dysgenesis, such as the various conditions involving lissencephaly [Dobyns et al, 1984], should be approached with the many roles of peroxisomes in mind. The importance of lipid metabolism in embryogenesis should be given increased emphasis, particularly since certain cellular growth factors contain glycerolipid cofactors [Cooper et al, 1984].

It is worth emphasizing the role of clinical genetics in defining ZS as an entity and in providing a useful mutant that will not contribute much to the understanding of peroxisome function. Careful morphometric evaluation and clinical follow-up should be components in the registry of patients with peroxisomal disorders. It is unfortunate that an established syndrome like ZS has the rather fragmentary record of clinical and biochemical findings (Table III) which limit our attempts to judge therapy. Without increased emphasis, the "experiments of nature" that human malformation syndromes represent will either be unobserved or their results inadequately recorded.

\section{REFERENCES}

Agamanolis DP, Robinson HB, Timmons GD (1976): Cerebro-hepato-renal syndrome: Report of a case with histochemical and ultrastructural observations. I Neuropathol Exp Neurol 35:226-246.

Arneson DW, Tipton RE, Ward JC (1982): Hyperpipecolic acidemia: Occurrence in an infant with clinical findings of the cerebrohepatorenal (Zellweger) syndrome. Arch Neurol 39:713-716.

Bartoletti S, Armfield SI III, Ledesma-Medina J (1978): The cerebro-hepato-renal (Zellweger's) syndrome: Report of four cases. Radiology 127:741-745.

Benke PJ, Reyes PF, Parker JC Jr (1981): New form of adrenoleukodystrophy. Hum Genet 58:204-208.

Bowen P, Lee CSN, Zellweger H, Lindenberg R (1964): A familial syndrome of multiple congenital defects. Bull Johns Hopkins Hosp 114:402-414.

Brown FR, McAdams AJ, Cummins JW, Konkol R, Singh I, Moser AB, Moser HW (1982): Cerebrohepato-renal (Zellweger) syndrome and neonatal adrenoleukodystropy: Similarities in phenotype and accumulation of very long chain fatty acids. John Hopkins Med J 151:344-361.

Brun A, Gilboa M, Meeuwissen GW, Nordgren H (1978): The Zellweger syndrome: Subcellular pathology, neuropathology, and the demonstration of pneumocystis carinii pneumonitis in two siblings. Eur J Pediatr 127:229-245.

Cooper JA, Sefton BM, Hunter T (1984): Diverse mitogenic agents induce the phosphorylation of two related 42,000 dalton proteins on tyrosine in quiescent chick cells. Mol Cell Biol 4:30-37.

Danks DM, Tippett P, Adams C, Campbell P (1975): Cerebro-hepato-renal syndrome of Zellweger: A report of eight cases with comments upon the incidence, the liver lesion, and a fault in pipecolic acid metabolism. J Pediatr 86:382-387.

Datta NS, Wilson GN, Hajra AK (1984): Deficiency of enzymes catalyzing the biosynthesis of glycerol- 
ether lipids in Zellweger syndrome: A new category of metabolic disease involving the absence of peroxisomes. $\mathrm{N}$ Engl $\mathrm{J}$ Med 311 : 1080-1083.

DeLeon GA, Grover WD, Huff DS, Morinigo-Mestre G, Punnett HH, Kistenmacher ML (1977): Globoid cells, glial nodules, and peculiar fibrillary changes in the cerebrohepato-renal syndrome of Zellweger. Ann Neurol 2:474-484.

Dobyns WB, Stratton RF, Greenberg F (1984): Syndromes with lissencephaly. Miller-Dieker and Normal-Roberts syndromes and isolated lissencephaly. Am J Med Genet 18:509-526.

Evrard P, Caviness VS Jr. Prats-Vinas J, Lyon G ( 1978): The mechanism of arrest of neuronal migration in the Zellweger Malformation: An hypothesis based upon cytoarchitectonic analysis. Acta Neuropathol (Berl) $41: 109-117$

Folch J, Lees M, Sloane-Stanley GH (1957): A simple method for the isolation and purification of total lipids from animal tissues. J. Biol Chem 226:497-509.

Garzuly F, Szabo L, Kadas L (1974): Neuronale migrationsstorung bei cerebrohepato-renalem syndrome "Zellweger." Neuropediatrics 5:318-328.

Gatfield PD, Talleer E, Hinton GG, Wallace AC, Abdelnour GM, Haust MD (1968): Hyperpipecolatemia: A new metabolic disorder associated with neuropathy and hepatomegaly: A case study. Can Med Assoc J 99:1215:1233.

Gilchrist KW, Gilbert EF, Goldfarb S, Goll U, Spranger JW, Opitz JM (1976): Studies of malformation syndromes of man XIB: The cerebro-hepato-renal syndrome of Zellweger: Comparative pathology. Eur J Pediatr 121:99-118.

Goldfischer S (1982); Peroxisomes and human metabolic diseases. Ann NY Acad Sci 386:170-181.

Goldfischer S, Moore CL, Johnson AB, Spiro AJ, Valsamis MP, Wisniewski HK, Ritch RH, Norton WT, Rapin I, Gartner LM (1973): Peroxisomal and mitochondrial defects in the cerebro-hepatorenal syndrome. Science 182:62-64.

Goldfischer S, Collins J, Rapin I, Coltoff-Schiller B, Change C-H, Nigro M, Black VH, Javitt NB, Moser HW, Lazarow PB (1985): Peroxisomal defects in neonatal-onset and X-linked adrenoleukodystrophies. Science 227:67-70.

Govaerts L, Monnen L, Melis T, Trijbels F (1984): Disturbed adrenocortical function in cerebro-hepatorenal syndrome of Zellweger. Eur J Pediatr 143:10-12.

Govaerts L, Monnen L, Tegelaers W, Trijbels F, van Raay-Selten A (1983): Cerebro-hepato-renal syndrome of Zellweger: Clinical symptoms and relevant laboratory findings in 16 patients. Eur $\mathrm{J}$ Pediatr 139:125-128.

Gustafsson J, Gustavson K-H, Karlaganis G, Sjovall J (1983): Zellweger's cerebro-hepato-renal syndrome-variations in expressivity and in defects of bile acid synthesis. Clin Genet 24:313-319.

Haas JE, Johnson ES, Farrell DL (1982): Neonatal-onset adrenoleukodystrophy in a girl. Am Neurol 12:449-457.

Hajra AK (1968): biosynthesis of acyldihydroxyacetone phosphate in guineapig liver mitochondria. J Biol Chem 243:3458-3465.

Hajra AK, Bishop JE (1982): Glycerolipid biosynthesis in peroxisomes via the acyl dihydroxyacetone phosphate pathway. Ann NY Acad Sci 386:170-181.

Hajra AK, Burke CL, Jones CL (1979): Subcellular localization of acetyl CoA: Kihydroxyacetone phosphate acyltransferase in rat liver peroxisomes (microbodies). J Biol Chem 254: 10896-10900.

Hajra AK, Datta NS, Jackson LG, Moser AB, Moser HW, Larsen JW Jr, Powers J (1985): Prenatal diagnosis of Zellweger cerebrohepatorenal syndrome. N Engl J Med 312:445-446.

Hanson RJ, Szczepanik-van Leeuwen P, Williams GC, Grabowski G, Sharp HL (1979): Defects of bile acid synthesis in Zellweger's syndrome. Science 203:1107-0000.

Heymans HSA, Schutgens RBH, Tan R, van den Bosch H, Borst P (1983): Severe plasmalogen deficiency in infants without peroxisomes (Zellweger syndrome). Nature 306:69-70.

Hittner HM, Kretzer FL, Mehta RS (1981): Zellweger syndrome: Lenticular opacities indicating carrier status and lens abnormalities characteristic of homozygotes. Arch Ophtalmol 99:1977-1982.

Horrock LA (1968): The alk-l-enyl group content of mammalian myelin phosphoglycerides by quantitative two-dimensional thin-layer chromatography. J Lipid Res 9:469-472.

Jaffe R, Crumrine P, Hashida Y, Moser HW (1982): Neonatal adrenoleukodystrophy: Clinical, pathologic, and biochemical delineation of a syndrome affecting both males and females. Am $J$ Pathol 108: $100-111$.

Jan JE, Hardwick DF, Lowry RB, McCormick AQ (1970): Cerebro-hepato-renal syndrome of Zellweger. Am J Dis Child 119:274-277. 
Kawamura N, Moser HW, Kishimoto Y (1981): Very long chain fatty acid oxidation in rat liver. Biochem Biophys Res Commun 99:1216-1225.

Kelley RI (1983): The cerebrohepatorenal syndrome of Zellweger, morphologic and metabolic aspects. Am J Med Genet 16:503-517.

Kishimoto Y, Moser HW, Kawamura N, Platt M, Pallante SL, Fenselau C (1980): Adrenoleukodystrophy: Evidence that abnormal very long chain fatty acids of brain cholesterolesters are of exogenous origin. Biochem Biophs Res Commun 96:69-76.

Liu HM, Bangaru BS, Kidd J, Boggs J (1976): Neuropathological considerations in cerebro-hepato-renal syndrome (Zellweger's syndrome). Acta Neuropathol (Berl) 34:115-123.

Mangold HK (1973): Biological effects and biomedical applications of alkoxy lipids. In Snyder, F. (ed): "Ether Lipids." New York: Academic Press, p. 157.

Moser AE, Singh I, Brown FR III, Solish GI, Kelley RI, Benke PJ, Moser HW (1984): The cerebrohepatorenal (Zellweger) syndrome: Increased levels and impaired degradation of very-long-chain fatty acids and their use in prenatal diagnosis. N Engl J Med 310:1141-1146.

Novikoff AB, Novikoff PM (1982): Microperoxisomes and peroxisomes in relation to lipid metabolism. Ann NY Acad Sci 386:138-150.

Opitz JM, ZuRhein GM, Vitale L, Shahidi NT, Howe JJ, Chou SM, Shanklin DR, Sybers HD, Dood AR, Gerritsen T (1969): The Zellweger syndrome (Cerebrohepatorenal syndrome) Birth Defects V(II):144-158.

Passarge E, McAdams AJ (1967): Cerebrohepatorenal syndrome: A newly recognized hereditary disorder of multiple congenital defects, including sudanophilic leukodystrophy, cirrhosis of the liver, and polycystic kidneys. J Pediatr 71:691-702.

Patton RG, Christie DL, Smith DW, Beckwith JB (1972): Cerebro-hepato-renal syndrome of Zellweger. Am J Dis Child 124:840-844.

Poulos A, Sharp P, Whiting M (1984): Infantile Refsum's disease (phytanic acid storage disease): A variant of Zellweger's syndrome? Clin Genet 26:579-586.

Poznanski AK, Nosanchuk JS, Baublis J, Holt JF (1970): The cerebrohepatorenal syndrome (CHRS) Am J Roent 109:313-322.

Punnett HH, Kirkpatrick JA Jr (1968): A syndrome of ocular abnormalities, calcification of cartilage, and failure to thrive. J Pediatr 73:602-606.

Reddy JK, Warren JR, Reddy MK, Lalwani ND (1982): Hepatic and renal effects of peroxisome proliferators: Biological implications. Ann NY Acad Sci 386:81-110.

Schrakamp G, Schutgens RBH, Wanders RJA, Heymans HSA, Tager JM, Van den Bosch H (1985): The cerebro-hepato-renal (Zellweger) syndrome. Impaired de novo biosynthesis of plasmalogens in cultured skin fibroblasts. Biochem Biophys Acta 833:170-174.

Schutgens RBH, Romeyn GJ, Wanders RJA, van den Bosch H, Schrakamp G, Heymans HSA (1984): Deficiency of acyl CoA: Dihydroxyacetone phophate acyltransferase in patients with Zellweger (cerebro-hepato-renal) syndrome. Biochem Biophys Res Commun 120:179-184.

Solish GI, Moser HW, Renger LD, Moser AE, Tiffany C, Schutta E (1985): The prenatal diagnosis of the cerebro-hepato-renal syndrome of Zellweger. Prenat Diagn 5:27-34.

Sommer A, Bradel EJ, Hamoudi AB (1974): The cerebro-hepato-renal syndrome (Zellweger's syndrome). Biol Neonate 25:219-229.

Smith DW, Opitz JM, and Inhorn SI (1965): A syndrome of multiple developmental defects including polycystic kidneys and intrahepatic biliary dysgenesis in 2 siblings. J Pediatr 67:617-624.

Thomas GH, Haslam RHA, Batshaw ML, Capute AJ, Neidengard L, Ransom JL (1975): Hyperpipecolic acidemia associated with hepatomegaly, mental retardation, optic nerve dysplasia and progressive neurological disease. Clin Genet 8:376-382.

Uhlrich J, Herschkowitz N, Heitz P, Sigrist T, Baerlocher P (1978): Adrenoleukodystrophy: Preliminary report of a connatal case. Acta Neuropathol 43:77-83.

Versmold HT, Bremer HJ, Herzog V, Siegel G, von Bassewitz DB, Irle U, van Voss H, Lombeck I, Brauser B (1977): A metabolic disorder similar to Zellweger syndrome with hepatic acatalasia and absence of peroxisomes, altered content and redox state of cytochromes, and infantile cirrhosis with hemosiderosis. Eur J Pediatr 124:261-275.

Vincens A, Guillat J-C, Gatin G, Rodier J, Graveleau D (1973): A propos d'un cas de syndrome de zellweger (syndrome hepato-cerebro-renal). Ann Pediatr 20:553-560.

Vitale L, Opitz JM, Shahidi NT (1969): Cogenital and familial iron overload. N Engl J Med 280:642645. 


\section{2}

\section{Wilson et al}

Volpe JJ, Adams RD (1972): Cerebro-hepato-renal syndrome of Zellweger: An inherited disorder of neuronal migration. Acta Neuropathol (Berl) 20:175-198.

Vuia O, Hager H, Rupp H, Koch F (1973): The neuropathology of a peculiar form of cerebro-renal syndrome in a child. Neuropediatrics 4:322-337.

Wanders RJA, Kos M, Roest B, Meijer AJ, Schrakamp G. Heymans HSA, Tegelaers WHH, van den Bosch H, Schutgens RBH, Tager JM (1984): Activity of peroxisomal enzymes and intracellular distribution of catalase in Zellweger syndrome. Biochem Biophs Res Commun 123:1054-1061.

Williams JP, Secrist L, Fowler GW, Gwinn JL, Dumars KC (1972): Roentgenographic features of the cerebrohepatorenal syndrome of Zellweger. Am J Roent 115:607-610.

Wood R, Snyder F (1968): Quantitative determination of alk-1-enyl and alkyl glycerol ethers in neutral lipids and phospholipids. Lipids 3:129-135.

Edited by James F. Reynolds 